\title{
Individual and household correlates of Helicobacter pylori infection among Young Ethiopian children in Ziway, Central Ethiopia
}

Kayla Schacher ${ }^{1}$, Hannah Spotts ${ }^{1}$, Caroline Correia' ${ }^{1}$ Sosina Walelign ${ }^{2}$, Mehret Tesfaye $^{2}$, Kassu Desta², Aster Tsegaye ${ }^{2}$ and Bineyam Taye ${ }^{1 *}$

\begin{abstract}
Background: Investigating distinct individual- and household-level risk factors for acquiring Helicobacter pylori (H. pylori) infection can inform disease prevention efforts and implicate possible routes of transmission. This study determined the magnitude of $\mathrm{H}$. pylori infection among schoolchildren in Ziway, central Ethiopia and identified personal and household correlates of $\mathrm{H}$. pylori infection in young Ethiopian children.

Methods: A total of 434 schoolchildren participated in this cross-sectional study. Infection status was assessed using antigen and antibody rapid tests. Demographic and lifestyle information was obtained from parents via an interviewer-led questionnaire. Univariate and multivariate logistic regressions were performed to assess the relationships between potential individual- and household-level risk factors and H. pylori infection.

Results: The prevalence of $H$. pylori infection was $65.7 \%$ (285/434). Of the personal variables assessed, the age group 10-14 years was found to be significantly associated with higher odds of H. pylori infection in univariate analysis (COR $=2.22,95 \% \mathrm{Cl}: 1.06-4.66, p=0.03)$ and remained positively correlated after adjusting for confounding factors. Of the household-level factors explored, having a traditional pit or no toilet was found to be significantly associated with 3.93-fold higher odds of $H$. pylori infection ( $A O R=3.93,95 \% \mathrm{Cl}: 1.51-10.3, p=0.01$ ), while the presence of smokers in the household was associated with $68 \%$ lower odds of infection (AOR $=0.32,95 \% \mathrm{Cl}$ : 0.11 $0.89, p=0.03)$.

Conclusion: This study from a developing country provides additional evidence for older age as a personal risk factor for $\mathrm{H}$. pylori infection and identifies correlations between socioeconomic and sanitation household factors and positive childhood infection status. The associations reported here support the hypothesized fecal-oralroute of transmission for H. pylori.
\end{abstract}

Keywords: H. pylori, Risk factors, Children, Ethiopia

* Correspondence: btaye@colgate.edu

'Department of Biology, Colgate University, 214 Olin Hall, 13 Oak Dr., Hamilton, NY 13346, USA

Full list of author information is available at the end of the article

(c) The Author(s). 2020 Open Access This article is licensed under a Creative Commons Attribution 4.0 International License, which permits use, sharing, adaptation, distribution and reproduction in any medium or format, as long as you give appropriate credit to the original author(s) and the source, provide a link to the Creative Commons licence, and indicate if changes were made. The images or other third party material in this article are included in the article's Creative Commons licence, unless indicated otherwise in a credit line to the material. If material is not included in the article's Creative Commons licence and your intended use is not permitted by statutory regulation or exceeds the permitted use, you will need to obtain permission directly from the copyright holder. To view a copy of this licence, visit http://creativecommons.org/licenses/by/4.0/ The Creative Commons Public Domain Dedication waiver (http://creativecommons.org/publicdomain/zero/1.0/) applies to the data made available in this article, unless otherwise stated in a credit line to the data. 


\section{Background}

Helicobacter pylori (H. pylori) is a pathogenic bacterium that infects human gastric mucosa [1]. It is known to be one of the leading causes of dyspepsia, active gastritis, peptic ulcers, and gastric adenocarcinomas [1]. Because of its role in gastric cancers, it is classified as a World Health Organization Group 1 carcinogen [2]. Nearly one half of the global population is infected with $H$. pylori, with some countries reporting over $80 \%$ infection rates $[3,4]$. Although prevalence rates have been generally declining in recent years, infection remains more prevalent in developing countries in comparison to developed countries $[3,4]$. The reasons for this are not yet fully established, though are speculated to be related to poorer sanitation and living conditions in resourcelimited settings [3].

Close person-to-person contact, especially between family members living together, has been shown to be important for $H$. pylori transmission [5, 6]. The exact mode of person-to-person transmission remains unclear though, with literature proposing both oral-oral and fecal-oral routes. Although $H$. pylori has been detected in dental plaque, saliva, gastric juice, and fecal matter, samples outside of the stomach have proven difficult to culture $[7,8]$. Identifying associated risk factors for infection can create a more comprehensive understanding of probable $H$. pylori transmission mechanisms.

Most $H$. pylori infections are acquired during childhood and persist into adulthood [9]. Infection often remains latent for years, with symptomatic disease developing up to several decades later [1]. Accordingly, H. pylori transmission is more highly associated with childhood living conditions than adult living conditions $[9,10]$. Previous studies have thus sought to identify select risk factors for $H$. pylori infection by examining childhood environments [10-15]. Common risk factors examined in these studies include age, indicators of socioeconomic status, and poor hand and cooking sanitation [10-16]. Both individual and familial characteristics have been shown to influence infection status. Investigating separate personal- and household-level risks for acquiring $H$. pylori infection can elucidate appropriate levels of disease prevention efforts. While personal attributes are crucial to investigate, factors affecting entire households have a greater impact on the health of families and groups of people living in close proximity. Focusing on distinct household risk factors can help inform public health interventions that are able to prevent a comparatively larger number of cases.

Despite the unequal worldwide distribution of $H$. pylori infection, previous studies on risk factors for childhood infection have almost mostly been carried out in industrialized countries [10-15]. More research needs to be done to identify and compare risk factors in children in more resource-limited settings, as these are the demographics with the highest rates of infection. $H$. pylori prevalence is comparatively understudied in many African countries, though the studies that have been completed show higher than average prevalence rates $[3,4$, 17, 18]. This makes studying childhood H. pylori infection in these countries important for disease surveillance and intervention. Understanding which contributing factors are inherent or mutable on the personal and household levels will enable public health workers to effectively maximize prevention by adding important clarifying details to the preexisting body of knowledge regarding $H$. pylori infections. This cross-sectional study therefore aimed to determine the magnitude of $H$. pylori infection among schoolchildren in Ziway, central Ethiopia and provide evidence for distinct personal and household risk factors associated with positive $H$. pylori childhood infection status.

\section{Methods \\ Study area and design}

This study was conducted in Ziway, Ethiopia along Lake Ziway located $160 \mathrm{~km}$ south of the country capital, Addis Ababa. Ziway has a population of 43,660 per the 2007 census and has experienced population and economic growth since its establishment in 1961. The population of Ziway is majority male (52.6\%) and Orthodox Christian (51.0\%). Participant study eligibility included children less than 15 years old who lived in Ziway and were enrolled in primary school. Data was collected from June 6 to July 30, 2016 at four different locations: Sher Elementary School, Sher Ethiopia Hospital, Batu Hospital, and Batu Health Clinic. A cross-sectional study was designed to examine the prevalence of $H$. pylori in Ziway schoolchildren as well as assess risk factors for acquiring H. pylori infection. A convenient sampling technique was used in order to enroll participants in the study; a child's school attendance on a particular day determined participation. Enrollment in mass deworming programs is based on World Health Organization (WHO) recommendation, in which anthelmintic drugs are administrated to all schoolchildren regardless of their demographic difference.

\section{Data collection and laboratory analyses}

Informed consent forms were signed by the parents of children involved in the study. Demographic and lifestyle information was collected through a questionnaire developed previously [19], and administered to the parents by a trained interviewer. Demographic questions included information on mother's education, occupation, and place of residence. Lifestyle information included household size, sanitary conditions, child health practices, and latrine usage. Deworming status was ascertained from 
school records. Active H. pylori infection was determined using an antigen rapid test enzyme immunoassay (Human Helicobacter Pylori Rapid Test Cassette Antigen RapiCard InstaTest, Diagnostic Automation Inc., USA). Each participant was given a leak-proof plastic container and clear instructions on how to collect a fecal sample. Once collected, samples were placed in a container with $10 \%$ formalin and transported to Sher Ethiopia Hospital for detection of $H$. pylori antigens. For this, a small amount of stool was homogenized with buffer solution and added to test wells. A monoclonal mix of anti- $H$. pylori antibodies was used for the capture antibody and a mix of monoclonal peroxidaseconjugated anti- $H$. pylori antibodies was used for the detection antibody. The test was read after 15 min of contact with antibodies. A positive result was defined as the presence of two lines, even if the test line was noticeably fainter than the control line. A negative result was defined as the presence of only the control line. The sensitivity and specificity of the test are 94 and 96.7\%, respectively.

An antibody rapid test (Diagnostic Automation Inc., USA) was used to detect any past or present $H$. pylori infections through a double antigen chromatographic lateral flow immunoassay. This test is unable to distinguish between current and past infection. A $5 \mathrm{~mL}$ whole blood sample was collected from each participant using sterile disposable syringes. Within two hours of blood collection, serum samples were separated at Sher Hospital laboratory to detect presence of $H$. pylori antibodies. For this assay, each test well received 1-2 drops of serum and was read $15 \mathrm{~min}$ after the serum was added. A positive result was defined as the presence of two lines, even if the test line was noticeably fainter than the control line. A negative result was defined as the presence of only the control line.

\section{Exposure definitions}

Both personal and household-level risk factors were examined in order to understand the different levels of risk for H. pylori infection. Personal factors are individual attributes or behaviors that can affect the likelihood of developing a disease. Personal variables examined in this study include, but are not limited to, age, sex, medication history, and laboratory test results. All individual variables were able to be measured directly from participants.

Household factors are familial living conditions that affect health opportunities and outcomes for all people living in the same household. Some of the household factors assessed include, but are not limited to, indicators of socioeconomic status, housing conditions, cooking practices, water source, sanitation, and animal ownership. Several household factors are difficult to measure directly, so in these cases proxy measurements were used as estimates. Socioeconomic status was determined using maternal education and household electricity use. Quality of housing materials was defined by wall type and floor type. Housing conditions were evaluated by the presence of a bed for the child and household cooking location. Sanitation was assessed through type of latrine in household and materials used for cooking.

\section{Outcome definitions}

A positive stool antigen rapid test indicates bacterial antigens in the body and is used in this study to define current $H$. pylori infection. A positive antibody rapid test from a blood serum sample indicates antibodies for the bacteria are present in the bloodstream following infection and is used in this study to define past infection. Positive $H$. pylori infection status is classified as a positive outcome for either test signifying $H$. pylori infection at some point during the child's life.

\section{Statistical analysis}

Data were entered, cleaned, and coded for analysis using SPSS Statistics (IBM Corp., Armonk, N.Y., USA). Descriptive statistics were used to characterize data and assess distribution of study variables. Univariate logistic regressions were completed in order to identify factors to include in further analysis. Multivariate logistic regressions were completed to assess the relationships between potential risk factors and $H$. pylori infection status after adjusting for confounding variables. Both direct multivariate analysis using all factors and stepwise regression including only variables associated with positive $H$. pylori infection status at $p<0.3$ during univariate analysis were performed. Odds ratios were calculated to determine the magnitude of associations for each risk factor. Statistical significance was defined as $p<0.05$. Similar patterns of demographic and lifestyle distributions were observed among study subject who had complete outcome data and all respondents using sensitivity analysis (data not shown).

\section{Data quality assurance}

Questionnaires were inspected by two separate reviewers for completeness and consistency of biological data. Incomplete surveys were returned to participants to complete. Physical samples were analyzed immediately after collection. Two senior lab technicians read the data. Quality control samples were used for both the rapid antigen test and rapid antibody test. 
Table 1 Distribution of sociodemographic factors in schoolchildren in Ziway, central Ethiopia

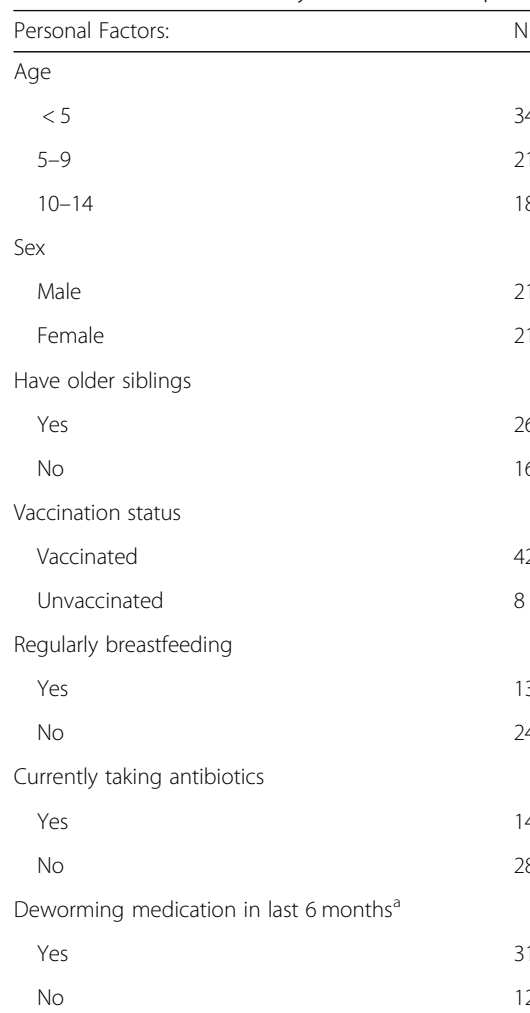

Hemoglobin count $\mathrm{g} / \mathrm{dL}$

$<11.5$

$\geq 11.5$

$\%$

ousehold Factors:

Maternal education

Formal

Non-formal

Maternal occupation

Housewife

Employed

Socioeconomic status ${ }^{b}$

Good

Poor

Lack of paracetamol

Yes

No

Residence location

$$
\text { Rural }
$$

Urban

Number of people in house

$$
\begin{aligned}
& 2-5 \\
& >5
\end{aligned}
$$

Smokers in house

$$
\text { Yes }
$$

No
34

210 $\%$ .

\begin{tabular}{|c|c|c|}
\hline Personal Factors: & $\mathrm{N}$ & $\%$ \\
\hline \multicolumn{3}{|l|}{ Housing materials $^{d}$} \\
\hline Good & 369 & 85.0 \\
\hline Poor & 65 & 15.0 \\
\hline \multicolumn{3}{|c|}{ Housing conditions $^{\mathrm{e}}$} \\
\hline Good & 384 & 88.5 \\
\hline Poor & 50 & 11.5 \\
\hline \multicolumn{3}{|l|}{ Cooking location } \\
\hline Inside house & 332 & 76.7 \\
\hline Outside house & 101 & 23.3 \\
\hline \multicolumn{3}{|c|}{ Cooking with natural materials $^{f}$} \\
\hline Yes & 320 & 73.7 \\
\hline No & 114 & 26.3 \\
\hline
\end{tabular}

95.8
Table 1 Distribution of sociodemographic factors in schoolchildren in Ziway, central Ethiopia (Continued)

Gas or electric cooking

Yes 91

No $\quad 343$

Any electricity use in household

Yes

$412 \quad 94.9$

No

Cat or dog ownership

Yes

No

42.6

Farm animal ownership ${ }^{9}$

Yes

No

Any animal ownership

Yes

No

Main water source

Piped

Well/natural water source

Type of toilet

Flush or ventilated pit

Traditional pit or none

Waste disposal

Pit/field/other

Burning/garbage bin

Sanitation ${ }^{\text {h }}$

Good

59.9

Poor

260

40.1

${ }^{\mathrm{a}}$ Deworming status was defined, received single dose (500 $\mathrm{mg}$ of mebendazole) as part of the mass school-based deworming programs in the past 6 months as evidenced form school records

bood socioeconomic status defined as formal maternal education and any household electricity use

65.0 Clack of paracetamol defined as lack of affordability or availability

Tack of paracetamol defined as lack of affordability or availability
dpoor housing materials defined as mud and wood walls and uncovered

mud floor

e poor housing conditions defined as no child bed and cooking inside main living area in house

fnatural materials defined as dung, leaves, and wood

${ }^{9}$ farm animals defined as hen, cow/ox, sheep, horse, goat, pig, and mule/donkey
hpoor sanitation defined as tradition pit or no toilet and using dung for cooking 


\section{Results}

Sociodemographic distribution of study participants

A total of 434 schoolchildren participated in this study. The distribution of personal and household factors within the study population is summarized in Table 1. Of the children who participated, $7.90 \%$ were less than 5 years old, $48.7 \%$ ages $5-9$, and $43.4 \%$ ages $10-14$. A slight majority were male (50.5\%) and most were not currently taking antibiotics (66.4\%). Urban living was most common (96.3\%) so the majority of families used electricity in the household (94.9\%), although $73.7 \%$ of families cooked with natural materials and only $21.0 \%$ with gas or electricity. About $40 \%$ of households were classified as having poor sanitation, though $94.9 \%$ had a traditional pit or no toilet. Animal ownership was common $(63.4 \%)$ with $42.6 \%$ of households owning a cat or dog and $34.6 \%$ owning a farm animal. Only a small percent $(4.2 \%)$ of children lived in a house with a cigarette smoker.

\section{Prevalence of $H$. pylori infection}

Positive $H$. pylori infection status was defined as either current or previous infection. As seen in Table 2, the prevalence of $H$. pylori infection among tested schoolchildren was $65.7 \%(285 / 434)$.

\section{Association of Personal Factors and $\boldsymbol{H}$. pylori infection}

The crude associations between personal factors and $H$. pylori infection were assessed using univariate logistic regressions (Table 3). Of all the personal variables examined, univariate analysis found that the age group 10-14 showed statistically significant increased odds of infection $(\mathrm{COR}=2.22,95 \% \mathrm{CI}$ : $1.06-4.66, p=0.03)$, while age group 5-9 demonstrated a borderline significant correlation $(\mathrm{COR}=1.88,95 \% \mathrm{CI}: 0.91-3.89, p=0.09)$. Females $(\mathrm{COR}=1.32$, 95\% CI: 0.89-1.97, $p=0.20)$ and those currently taking antibiotics $(\mathrm{COR}=1.36,95 \% \mathrm{CI}: 0.90-2.07$, $p=0.14$ ) were also both associated with higher odds of $H$. pylori infection, though both failed to reach statistical significance.

Direct and stepwise multivariate logistic regressions were performed in order to determine any associations with $H$. pylori infection after adjusting for confounding factors. Direct multivariate analysis yielded similar trends as in univariate analysis, except none of the associations in this regression model reached statistical

Table 2 Prevalence of $H$. pylori infection among schoolchildren in Ziway, central Ethiopia

\begin{tabular}{lll}
\hline H. pylori status & $\mathrm{N}$ & $\%$ \\
\hline Positive $^{\text {a }}$ & 285 & 65.7 \\
Negative & 149 & 34.3 \\
\hline
\end{tabular}

${ }^{a}$ positive infection status defined as positive result for either antibody or antigen test significance (Table 3). Vaccination status was the only variable with an OR that greatly changed from crude to adjusted, with unvaccinated children showing a moderately strong non-significant association with higher odds of $H$. pylori infection $(\mathrm{AOR}=2.13,95 \% \mathrm{CI}$ : 0.38-12.1, $p=0.39$ ). Stepwise multivariate analysis including only individual factors with a COR $p<0.3$ also yielded no statistically significant results, but again demonstrated that older age, female sex, and current antibiotic use were correlated with higher odds of $H$. pylori infection. Most ORs remained relatively stable throughout univariate and multivariate analysis.

\section{Association of Household Factors and $H$. pylori infection}

The crude associations between household-level factors and $H$. pylori infection were assessed using univariate logistic regressions. Out of all household variables assessed, univariate analysis found that having a traditional pit or no toilet was the only factor associated with statistically significant increased odds of $H$. pylori infection $(\mathrm{COR}=3.59,95 \% \mathrm{CI}: 1.47-8.77, p=0.01)$. Poor sanitation $(\mathrm{COR}=1.46,95 \% \mathrm{CI}: 0.95-2.25, p=0.08)$ and no household electricity use (COR $=1.87$, 95\% CI: $0.66-$ $5.05, p=0.25)$ were also correlated with slightly higher odds of infection, though failed to reach statistical significance. Conversely, cigarette smokers living in the household significantly decreased the odds of positive $H$. pylori infection status $(\mathrm{COR}=0.32,95 \% \mathrm{CI}: 0.12-0.84$, $p=0.02)$. Rural dwelling (COR $=0.51,95 \% \mathrm{CI}$ : $0.19-1.39$, $p=0.19)$ and cooking with natural materials (COR = 0.72 , 95\% CI: $0.45-1.14, p=0.16)$ were both associated with statistically insignificant decreased odds of $H$. pylori infection.

Direct and stepwise multivariate logistic regressions were performed in order to determine associations with $H$. pylori infection after adjusting for confounding factors (Table 4). Direct multivariate analysis yielded similar trends as in univariate analysis, with traditional pit or no toilet being significantly associated with positive $H$. pylori status $(\mathrm{AOR}=3.78,95 \% \mathrm{CI}: 1.40-10.3, p=0.01)$ and presence of household smokers significantly associated with negative infection status $(\mathrm{AOR}=0.35,95 \% \mathrm{CI}$ : $0.12-0.99, p=0.05)$. Poor socioeconomic status (AOR = 3.85, 95\% CI: 0.29-50.8. $p=0.31$ ), cat or dog ownership $(\mathrm{AOR}=2.15,95 \% \mathrm{CI}: 0.98-4.72, p=0.06)$, and farm animal ownership (AOR $=2.03,95 \% \mathrm{CI}: 0.72-5.70, p=0.18$ ) all showed increased moderate strengths of association with positive $H$. pylori infection status after adjustment, though failed to reach statistical significance. Informal maternal education $(\mathrm{AOR}=0.39,95 \% \mathrm{CI}: 0.03-5.05, p=$ 0.47 ), rural residence $(\mathrm{AOR}=0.40,95 \% \mathrm{CI}: 0.12-1.33$, $p=0.14$ ), and any animal ownership (AOR $=0.45,95 \%$ CI: $0.17-1.15, p=0.09)$ all showed statistically insignificant decreased odds of infection. Household factors with 
Table 3 Associations between personal factors and H. pylori infection status in schoolchildren in Ziway, central Ethiopia

\begin{tabular}{|c|c|c|c|c|c|c|c|c|c|c|c|c|c|}
\hline & Positive & H. pylori & Negative & H. pylori & & & & & & & & & \\
\hline & $\mathrm{N}$ & $\%$ & $N$ & $\%$ & COR & $(95 \% \mathrm{Cl})$ & $P$ & AOR & $(95 \% \mathrm{Cl})$ & $P$ & $\mathrm{AOR}^{\mathrm{a}}$ & $(95 \% \mathrm{Cl})$ & $P$ \\
\hline \multicolumn{14}{|l|}{ Age } \\
\hline$<5$ & 17 & 50.0 & 17 & 50.0 & 1 & - & - & 1 & - & - & 1 & - & - \\
\hline $5-9$ & 137 & 65.2 & 73 & 34.8 & 1.88 & $(0.91-3.89)$ & 0.09 & 1.77 & $(0.81-3.87)$ & 0.15 & 1.82 & $(0.87-3.80)$ & 0.11 \\
\hline $10-14$ & 129 & 69.0 & 58 & 31.0 & 2.22 & $(1.06-4.66)$ & 0.03 & 1.98 & $(0.88-4.44)$ & 0.10 & 2.07 & (0.98-4.39) & 0.06 \\
\hline \multicolumn{14}{|l|}{ Sex } \\
\hline Male & 137 & 62.6 & 82 & 37.4 & 1 & - & - & 1 & - & - & 1 & - & - \\
\hline Female & 148 & 68.8 & 67 & 31.2 & 1.32 & $(0.89-1.97)$ & 0.20 & 1.36 & $(0.90-2.04)$ & 0.15 & 1.34 & $(0.89-2.00)$ & 0.16 \\
\hline \multicolumn{14}{|c|}{ Have older siblings } \\
\hline Yes & 169 & 63.8 & 96 & 36.2 & 0.81 & $(0.54-1.22)$ & 0.32 & 0.76 & $(0.50-1.16)$ & 0.21 & - & - & - \\
\hline No & 115 & 68.5 & 53 & 31.5 & 1 & - & - & 1 & - & - & - & - & - \\
\hline \multicolumn{14}{|l|}{ Vaccination status } \\
\hline Vaccinated & 280 & 65.7 & 146 & 34.3 & 1 & - & - & 1 & - & - & - & - & - \\
\hline Unvaccinated & 5 & 62.5 & 3 & 37.5 & 0.87 & $(0.20-3.69)$ & 0.85 & 2.13 & $(0.38-12.1)$ & 0.39 & - & - & - \\
\hline \multicolumn{14}{|c|}{ Regularly breastfeeding } \\
\hline Yes & 95 & 36.4 & 43 & 34.1 & 1 & - & - & 1 & - & - & - & - & - \\
\hline No & 166 & 63.6 & 83 & 65.9 & 0.91 & $(0.58-1.42)$ & 0.66 & 0.93 & $(0.59-1.46)$ & 0.74 & - & - & - \\
\hline \multicolumn{14}{|c|}{ Currently taking antibiotics } \\
\hline Yes & 89 & 61.0 & 57 & 39.0 & 1 & - & - & 1 & - & - & 1 & - & - \\
\hline No & 196 & 68.1 & 92 & 31.9 & 1.36 & $(0.90-2.07)$ & 0.14 & 1.24 & $(0.80-1.91)$ & 0.34 & 1.26 & $(0.82-1.93)$ & 0.29 \\
\hline \multicolumn{14}{|c|}{ Deworming medication in last 6 months } \\
\hline Yes & 204 & 65.2 & 109 & 34.8 & 0.92 & $(0.59-1.44)$ & 0.73 & 0.91 & $(0.57-1.44)$ & 0.68 & - & - & - \\
\hline No & 81 & 66.9 & 40 & 33.1 & 1 & - & - & 1 & - & - & - & - & - \\
\hline \multicolumn{14}{|c|}{ Hemoglobin count $\mathrm{g} / \mathrm{dL}$} \\
\hline$<11.5$ & 10 & 58.8 & 7 & 41.2 & 0.74 & $(0.28-1.98)$ & 0.55 & 0.70 & $(0.22-2.25)$ & 0.55 & - & - & - \\
\hline$\geq 11.5$ & 275 & 65.9 & 142 & 34.1 & 1 & - & - & 1 & - & - & - & - & - \\
\hline
\end{tabular}

${ }^{\mathrm{a} A O R}$ includes only variables with $\mathrm{COR} p<0.3$

a COR $p<0.3$ were further examined in stepwise multivariate analysis to find similar results. Having a traditional pit or no toilet was correlated with 3.93-fold higher odds of $H$. pylori infection (AOR $=3.93,95 \% \mathrm{CI}$ : 1.51-10.3, $p=0.01$ ), while the presence of cigarette smokers in the household demonstrated $68 \%$ lower odds of infection (AOR $=0.32,95 \% \mathrm{CI}: 0.11-0.89, p=0.03$ ). Disposing of waste in pits or fields $(\mathrm{COR}=0.61,95 \% \mathrm{CI}$ : $0.37-1.02 . p=0.06)$ showed a borderline significant decrease in odds of infection. Associations were generally strengthened from univariate analysis to multivariate adjustment.

\section{Discussion}

This study identified the prevalence of $H$. pylori infection in central Ethiopian schoolchildren and provides additional evidence for associations between distinct personal and household correlates and infection status. Positive infection status was significantly associated with older age at the individual level and having a traditional pit or no toilet at the household level. Presence of smokers in the household showed statistically significant decreased odds of infection. There was a borderline significant negative correlation between infection and pit or field waste disposal as well.

The $H$. pylori prevalence rate in schoolchildren in Ziway, Ethiopia was $65.7 \%$, signifying that over half of children less than 15 years old have been infected at some point in their life. This rate is higher than reports of the average global prevalence [3, 4], though comparable to recent studies in rural Ethiopia $[17,18]$. However, previously reported rates are inclusive of all age ranges, not just school-aged children. Assuming the trend of increased infection with older age continues, this suggests an overall higher disease prevalence in central Ethiopia than calculated in this study.

Of all the personal variables assessed, older age was associated with higher odds of positive $H$. pylori infection status, with ages 10-14 having a stronger association than ages 5-9. Older age is a common risk factor for $H$. 
Table 4 Associations between household factors and H. pylori infection status in school children in Ziway, central Ethiopia

\begin{tabular}{|c|c|c|c|c|c|c|c|c|c|c|c|c|c|}
\hline & Positive & H. pylori & Negative & H. pylori & & & & & & & & & \\
\hline & $\mathrm{N}$ & $\%$ & $\mathrm{~N}$ & $\%$ & COR & $(95 \% \mathrm{Cl})$ & $P$ & $\mathrm{AOR}$ & (95\% Cl) & $P$ & $A O R^{a}$ & $(95 \% \mathrm{Cl})$ & $P$ \\
\hline \multicolumn{14}{|l|}{ Maternal education } \\
\hline Formal & 162 & 64.0 & 91 & 36.0 & 1 & - & - & 1 & - & - & - & - & - \\
\hline Non-formal & 123 & 68.0 & 58 & 32.0 & 1.19 & $(0.80-1.79)$ & 0.40 & 0.39 & $(0.03-5.05)$ & 0.47 & - & - & - \\
\hline \multicolumn{14}{|l|}{ Maternal occupation } \\
\hline Housewife & 136 & 69.0 & 61 & 31.0 & 1.32 & $(0.88-1.97)$ & 0.18 & 1.24 & $(0.81-1.91)$ & 0.32 & 1.27 & $(0.84-1.94)$ & 0.26 \\
\hline Employed & 149 & 62.9 & 88 & 37.1 & 1 & - & - & 1 & - & - & 1 & - & - \\
\hline \multicolumn{14}{|l|}{ Socioeconomic status ${ }^{\mathrm{b}}$} \\
\hline Good & 155 & 63.3 & 90 & 36.7 & 1 & - & - & 1 & - & - & 1 & - & - \\
\hline Poor & 130 & 68.8 & 59 & 31.2 & 1.29 & $(0.86-1.91)$ & 0.23 & 3.85 & $(0.29-50.8)$ & 0.31 & 1.33 & $(0.86-2.06)$ & 0.21 \\
\hline \multicolumn{14}{|l|}{ Lack of paracetamol ${ }^{\mathrm{c}}$} \\
\hline Yes & 19 & 67.9 & 9 & 32.1 & 1.11 & $(0.49-2.52)$ & 0.80 & 1.05 & $(0.42-2.59)$ & 0.92 & - & - & - \\
\hline No & 266 & 65.5 & 140 & 34.5 & 1 & - & - & 1 & - & - & - & - & - \\
\hline \multicolumn{14}{|l|}{ Residence location } \\
\hline Rural & 8 & 50.0 & 8 & 50.0 & 0.51 & $(0.19-1.39)$ & 0.19 & 0.40 & $(0.12-1.33)$ & 0.14 & 0.39 & $(0.12-1.25)$ & 0.11 \\
\hline Urban & 277 & 66.3 & 141 & 33.7 & 1 & - & - & 1 & - & - & 1 & - & - \\
\hline \multicolumn{14}{|l|}{ Number of people in house } \\
\hline $2-5$ & 182 & 64.5 & 100 & 35.5 & 1 & - & - & 1 & - & - & - & - & - \\
\hline$>5$ & 103 & 67.8 & 49 & 32.2 & 1.16 & $(0.76-1.76)$ & 0.50 & 1.19 & $(0.75-1.90)$ & 0.45 & - & - & - \\
\hline \multicolumn{14}{|l|}{ Smokers in house } \\
\hline Yes & 7 & 38.9 & 11 & 61.1 & 0.32 & $(0.12-0.84)$ & 0.02 & 0.35 & $(0.12-0.99)$ & 0.05 & 0.32 & $(0.11-0.89)$ & 0.03 \\
\hline No & 276 & 66.7 & 138 & 33.3 & 1 & - & - & 1 & - & - & 1 & - & - \\
\hline \multicolumn{14}{|l|}{ Housing materials ${ }^{d}$} \\
\hline Good & 240 & 65.0 & 129 & 35.0 & 1 & - & - & 1 & - & - & - & - & - \\
\hline Poor & 45 & 69.2 & 20 & 30.8 & 1.21 & $(0.69-2.14)$ & 0.51 & 1.37 & $(0.73-2.59)$ & 0.33 & - & - & - \\
\hline \multicolumn{14}{|l|}{ Housing conditions ${ }^{\mathrm{e}}$} \\
\hline Good & 251 & 65.4 & 133 & 34.6 & 1 & - & - & 1 & - & - & & & \\
\hline Poor & 34 & 68 & 16 & 32 & 1.13 & $(0.60-2.12)$ & 0.71 & 0.98 & $(0.49-1.94)$ & 0.95 & - & - & - \\
\hline Cooking location & & & & & & & & & & & - & - & - \\
\hline Inside house & 222 & 66.9 & 110 & 33.1 & 1 & - & - & 1 & - & - & & & \\
\hline Outside house & 62 & 61.4 & 39 & 38.6 & 0.79 & $(0.50-1.25)$ & 0.31 & 0.69 & $(0.40-1.19)$ & 0.18 & - & - & - \\
\hline Cooking with natural materials ${ }^{f}$ & & & & & & & & & & & - & - & - \\
\hline Yes & 204 & 63.7 & 116 & 36.3 & 0.72 & $(0.45-1.14)$ & 0.16 & 0.65 & $(0.34-1.24)$ & 0.19 & 0.65 & $(0.39-1.09)$ & 0.10 \\
\hline No & 81 & 71.1 & 33 & 28.9 & 1 & - & - & 1 & - & - & 1 & - & - \\
\hline \multicolumn{14}{|l|}{ Gas or electric cooking } \\
\hline Yes & 62 & 68.1 & 29 & 31.9 & 1 & - & - & 1 & - & - & - & - & - \\
\hline No & 223 & 65.0 & 120 & 35.0 & 0.87 & $(0.53-1.42)$ & 0.58 & 0.90 & $(0.45-1.80)$ & 0.77 & - & - & - \\
\hline \multicolumn{14}{|l|}{ Any electricity use in household } \\
\hline Yes & 268 & 65.0 & 114 & 35.0 & 1 & - & - & 1 & - & - & 1 & - & - \\
\hline No & 17 & 77.3 & 5 & 22.7 & 1.87 & $(0.66-5.05)$ & 0.25 & 1.94 & $(0.47-7.98)$ & 0.36 & 2.53 & $(0.76-8.51)$ & 0.13 \\
\hline \multicolumn{14}{|l|}{ Cat or dog ownership } \\
\hline Yes & 125 & 67.6 & 60 & 32.4 & 1.16 & $(0.78-1.73)$ & 0.47 & 2.15 & $(0.98-4.72)$ & 0.06 & - & - & - \\
\hline No & 160 & 64.3 & 89 & 35.7 & 1 & - & - & 1 & - & - & - & - & - \\
\hline
\end{tabular}

Farm animal ownership ${ }^{9}$ 
Table 4 Associations between household factors and H. pylori infection status in school children in Ziway, central Ethiopia (Continued)

\begin{tabular}{|c|c|c|c|c|c|c|c|c|c|c|c|c|c|}
\hline & Positive & H. pylori & Negative & H. pylori & & & & & & & & & \\
\hline & $\mathrm{N}$ & $\%$ & $\mathrm{~N}$ & $\%$ & $\mathrm{COR}$ & $(95 \% \mathrm{Cl})$ & $P$ & AOR & $(95 \% \mathrm{Cl})$ & $P$ & $\mathrm{AOR}^{\mathrm{a}}$ & $(95 \% \mathrm{Cl})$ & $P$ \\
\hline Yes & 105 & 70.0 & 45 & 30.0 & 1.35 & $(0.88-2.06)$ & 0.17 & 2.03 & $(0.72-5.70)$ & 0.18 & 1.16 & $(0.51-2.68)$ & 0.72 \\
\hline No & 180 & 63.4 & 104 & 36.6 & 1 & - & - & 1 & - & - & 1 & - & - \\
\hline \multicolumn{14}{|l|}{ Any animal ownership } \\
\hline Yes & 183 & 66.5 & 92 & 33.5 & 1.11 & $(0.74-1.67)$ & 0.61 & 0.45 & $(0.17-1.15)$ & 0.09 & - & - & - \\
\hline No & 102 & 64.2 & 57 & 35.8 & 1 & - & - & 1 & - & - & - & - & - \\
\hline \multicolumn{14}{|l|}{ Main water source } \\
\hline Piped & 276 & 65.9 & 143 & 34.1 & 1 & - & - & 1 & - & - & - & - & - \\
\hline Well/natural water source & 9 & 60.0 & 6 & 40.0 & 0.78 & $(0.27-2.23)$ & 0.64 & 0.65 & $(0.17-2.59)$ & 0.55 & - & - & - \\
\hline \multicolumn{14}{|l|}{ Type of toilet } \\
\hline Flush or ventilated pit & 8 & 36.4 & 14 & 63.6 & 1 & - & - & 1 & - & - & 1 & - & - \\
\hline Traditional pit or none & 275 & 67.2 & 134 & 32.8 & 3.59 & $(1.47-8.77)$ & 0.01 & 3.78 & $(1.40-10.3)$ & 0.01 & 3.93 & $(1.51-10.3)$ & 0.01 \\
\hline \multicolumn{14}{|l|}{ Waste disposal } \\
\hline pit/field/other & 54 & 57.4 & 40 & 42.6 & 0.64 & $(0.40-1.02)$ & 0.06 & 0.61 & $(0.36-1.04)$ & 0.07 & 0.61 & $(0.37-1.02)$ & 0.06 \\
\hline burning/garbage bin & 231 & 67.9 & 109 & 32.1 & 1 & - & - & 1 & - & - & 1 & - & - \\
\hline \multicolumn{14}{|l|}{ Sanitation ${ }^{\text {h }}$} \\
\hline Good & 181 & 62.8 & 107 & 37.2 & 1 & - & - & 1 & - & - & 1 & - & - \\
\hline Poor & 104 & 71.2 & 42 & 28.8 & 1.46 & $(0.95-2.25)$ & 0.08 & 1.10 & $(0.46-2.60)$ & 0.83 & 1.15 & $(0.50-2.62)$ & 0.75 \\
\hline
\end{tabular}

${ }^{a} A O R$ includes only variables with $\operatorname{COR} \mathrm{p}<0.3$

${ }^{b}$ good socioeconomic status defined as formal maternal education and any household electricity use

ack of paracetamol defined as lack of affordability or availability

dpoor housing materials defined as mud and wood walls and uncovered mud floor

epoor housing conditions defined as no child bed and cooking inside main living area in house

f natural materials defined as dung, leaves, and wood

${ }^{9}$ farm animals defined as hen, cow/ox, sheep, horse, goat, pig, and mule/donkey

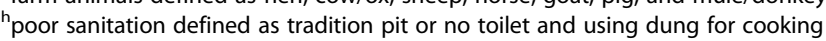

pylori infection cited in previous studies $[9,13-15,18$, 20-24]. There is no consensus yet whether this trend is due to cumulative increased risk over a lifetime [11,22] or decreased risk of infection in each subsequent birth cohort causing older cohorts to have higher infection rates comparatively $[20,24]$. Due to the nature of this study, the data presented here cannot support one hypothesis over the other.

Of all the household-level factors investigated, having a traditional pit or no toilet at all was significantly associated with 3.93-fold higher odds of $H$. pylori infection after adjusting for confounding factors. To date, contradictory literature exists regarding associations between latrine use and $H$. pylori infection status $[14,18]$. Having no toilet or a traditional pit could increase the possibility of contact with fecal material as compared to flush toilets or ventilated pits. In a study on traditional pit sanitation in Malawi, it was found that traditional pits can promote transmission of fecal-oral diseases due to lack of maintenance, poor disposal of feces, fouled washwater, and potential for pit surcharging [25]. Flush toilets, on the other hand, have been proposed as a mechanism for disease vector removal, which can help prevent further infection [14]. Since $H$. pylori can be detected in fecal material $[7,8]$, using traditional pits or no toilet may increase the potential for contact with the bacteria and facilitate infection. The significant association between toilet type and infection status reported in this study thus supports the proposed fecal-oral route of transmission for $H$. pylori. Accordingly, hygiene education and availability of alternative toilet types are potential areas of focus for disease control and prevention.

Strikingly, at the household level the presence of cigarette smokers in the household was significantly correlated with $68 \%$ decreased odds of $H$. pylori infection after adjusting for confounding factors. Previous studies have published conflicting results on the relationship between smoking as a personal attribute and $H$. pylori infection status [18, 26], though there is little data addressing infection rates in those living with smokers. In other developing African countries, smoking is more common among wealthy people [27]. Considering the small number of children in this study with family members that smoke, the presence of smokers in the household could thus be indicative of good socioeconomic status. Poorer socioeconomic status has been previously 
reported to be associated with increased $H$. pylori infection [11, 13, 21, 23], perhaps due to limited access to food, water, healthcare, and soap, among other things. This suggests that poverty and access to education may be possible targets for $H$. pylori prevention. Yet, as another explanation, Ogihara et al. proposed that chemical interactions between nicotine smoke and gastric mucosa can increase gastric acidity and mucosal atrophy, assisting in the auto-eradication of $H$. pylori infections [26]. It is unknown whether secondhand smoke exposure can lead to similar results. It is also possible that if adults who smoke have lower prevalence rates, there is less potential for household transmission. However, since this study does not address cigarette smoking as a personal variable, it remains unclear how the presence of smokers in the household influences $H$. pylori infection status. The effects of smoking on bacterial transmission in parents and children warrants further investigation.

Additionally, pit or field waste disposal was borderline significantly associated with decreased odds of positive H. pylori infection status as compared to burning or using garbage bins. A previous study in Asella, central Ethiopia describes limited access to door-to-door waste collection services in Ethiopian towns outside of the capital city [28]. Waste disposed in garbage bins in Ziway may thus not be frequently collected and instead stored in the home for extended periods of time. A study in Ghana found that storing solid waste in open containers in the home increased the presence of houseflies, which was in turn associated with increased gastrointestinal disease occurrence in children [29]. Similarly, Parente et al. found that the absence of garbage collection services is positively associated with $H$. pylori infection [30]. Houseflies are known vectors for disease transmission from fecal matter to food. It is thus possible that garbage bin waste disposal increases vector-borne transmission of $H$. pylori, again aligning with the proposed fecal-oral route of transmission. However, further investigation on waste management and disposal practices is needed to explore this possibility.

These findings should be interpreted in light of a few study limitations. First, a cross-sectional study design was used as there were no previously available baseline data on H. pylori infection status. Because of the observational nature of this study, it is difficult to conclude temporality and causality between personal and household variables and infection. A longitudinal study is needed to confirm our findings and assess the possibility of reverse causality. Additionally, only a small region of central Ethiopia was sampled, limiting the generalizability of the reported prevalence rates to the entire country. It is also probable that some residual confounding personal or household factors were excluded from analysis despite the large number of variables examined. Surveying the parents instead of the participants themselves limited the collection of information on child-specific variables such as frequency of handwashing after using the latrine or whether a child helps with food preparation. Our study participants were apparently healthy children enrolled in primary school, so the observed individual and household risk factors for $H$ pylori infection might be different if we included children who dropped out or never attended the school. A further limitation of the current study is that some subgroup categories had small sample sizes which led to wide and imprecise confidence intervals for those observed measures of association.

Despite these limitations, this study is the first to differentiate between personal- and household-level risk factors for $H$. pylori infection in a developing country. This distinction allows for a more thorough assessment of disease transmission and determination of which prevention efforts are most useful for disease control. The high rate of participation and large sample size used serve to strengthen the study findings. Additionally, because separate antigen and antibody rapid tests were performed, analyses were able to assess risk factors for both current and past infection.

\section{Conclusion}

Our data from a developing country provides additional support for older age as a personal risk factor for $\mathrm{H}$. pylori infection and identifies correlations between socioeconomic and sanitation household factors and positive childhood infection status. The associations reported here support the hypothesized fecal-oral route of transmission for $H$. pylori. Further longitudinal research is needed to establish causality and exact mechanisms.

\section{Abbreviations}

H. pylori: Helicobacter pylori; WHO: World Health Organization

\section{Acknowledgments}

We are grateful for the parents/guardians and children at each school who generously provided their information and thank the school administrators for facilitating stool collection and for their commitment during the fieldwork. We also thank two Colgate University undergraduate students, Katherine Titterton '17 and John Santiago '17, for their assistance with the fieldwork in Ethiopia. The views expressed here are those of the author(s) and not necessarily those of Colgate University or the Department of Medical Laboratory Sciences, College of Health Sciences, Addis Ababa University. The abstract has been presented as a poster on National Council on Undergraduate Research (NCUR) m(https://apps.cur.org/ncur2020/search/ Display_NCUR.aspx?id=114906).

\section{Authors' contributions}

BT conceived and designed the study, participated in fieldwork data collection, and wrote this manuscript. KS, HS, and CC performed data analysis and interpretation and prepared the preliminary results and draft of the manuscript. SW and MT participated in data collection, interpretation of data, and the critical review of the manuscript. AT and KD participated in data analysis and interpretation and critically reviewed the manuscript. All authors read and approved the final manuscript. 


\section{Funding}

Colgate University Research Council funded this study. The funding body had no role in study design; collection, analysis, and interpretation of data; writing of the report; or the decision to submit the paper for publication.

\section{Availability of data and materials}

The datasets analyzed in the current study will be available from the corresponding author upon reasonable request.

\section{Ethics approval and consent to participate}

Ethical clearance was given by Addis Ababa University Department of Medica Laboratory Science departmental research and ethics review committee. Prior to study enrollment, parents of participants gave written informed consent via signature or witnessed thumbprint. Written assent was received when appropriate. Confidentiality of participant identities was ensured during data analysis through the use of numerical identifiers. Electronic data were protected with passwords and hard copies were locked away during and after completion of the study.

\section{Consent for publication}

Not Applicable.

\section{Competing interests}

We declare that we do not have any conflicts of interest.

\section{Author details}

'Department of Biology, Colgate University, 214 Olin Hall, 13 Oak Dr., Hamilton, NY 13346, USA. ${ }^{2}$ Addis Ababa University, College of Health Sciences, Department of Medical Laboratory Science, Addis Ababa, Ethiopia.

Received: 20 February 2020 Accepted: 16 April 2020

Published online: 25 April 2020

\section{References}

1. Ernst PB, Gold BD. The disease spectrum of helicobacter pylori: the immunopathogenesis of gastroduodenal ulcer and gastric cancer. Annu Rev Microbiol. 2000:54:615-40.

2. Biological agents. Volume 100 B. A review of human carcinogens. IARC Monogr Eval Carcinog Risks Hum. 2012;100(Pt B):1-441.

3. Hooi JKY, Lai WY, Ng WK, Suen MMY, Underwood FE, Tanyingoh D, et al Global prevalence of helicobacter pylori infection: systematic review and meta-analysis. Gastroenterology. 2017;153(2):420-9.

4. Zamani M, Ebrahimtabar F, Zamani V, Miller WH, Alizadeh-Navaei R, ShokriShirvani J, et al. Systematic review with meta-analysis: the worldwide prevalence of helicobacter pylori infection. Aliment Pharmacol Ther. 2018; 47(7):868-76.

5. Kivi M, Johansson AL, Reilly M, Tindberg Y. Helicobacter pylori status in family members as risk factors for infection in children. Epidemiol Infect. 2005;133(4):645-52.

6. Malaty HM, Kumagai T, Tanaka E, Ota H, Kiyosawa K, Graham DY, et al. Evidence from a nine-year birth cohort study in Japan of transmission pathways of helicobacter pylori infection. J Clin Microbiol. 2000;38(5):1971-3.

7. Parsonnet J, Shmuely H, Haggerty T. Fecal and oral shedding of helicobacter pylori from healthy infected adults. Jama. 1999;282(23):2240-5.

8. Allaker RP, Young KA, Hardie JM, Domizio P, Meadows NJ. Prevalence of helicobacter pylori at oral and gastrointestinal sites in children: evidence for possible oral-to-oral transmission. J Med Microbiol. 2002;51(4):312-7.

9. Mitchell HM, Li YY, Hu PJ, Liu Q, Chen M, Du GG, et al. Epidemiology of helicobacter pylori in southern China: identification of early childhood as the critical period for acquisition. J Infect Dis. 1992;166(1):149-53.

10. Mendall MA, Goggin PM, Molineaux N, Levy J, Toosy T, Strachan D, et al. Childhood living conditions and helicobacter pylori seropositivity in adult life. Lancet. 1992;339(8798):896-7.

11. Malaty HM, Graham DY. Importance of childhood socioeconomic status on the current prevalence of helicobacter pylori infection. Gut. 1994;35(6):742-5.

12. McCallion WA, Murray LJ, Bailie AG, Dalzell AM, O'Reilly DP, Bamford KB. Helicobacter pylori infection in children: relation with current household living conditions. Gut. 1996:39(1):18-21.

13. Dore MP, Malaty HM, Graham DY, Fanciulli G, Delitala G, Realdi G. Risk factors associated with helicobacter pylori infection among children in a defined geographic area. Clin Infect Dis. 2002;35(3):240-5.
14. Ueda M, Kikuchi S, Kasugai T, Shunichi T, Miyake C. Helicobacter pylori risk associated with childhood home environment. Cancer Sci. 2003;94(10):914-8.

15. Szaflarska-Poplawska A, Soroczynska-Wrzyszcz A. Prevalence of helicobacter pylori infection among junior high school students in Grudziadz.. Poland. Helicobacter. 2019;24(1):e12552.

16. Ding Z, Zhao S, Gong S, Li Z, Mao M, Xu X, et al. Prevalence and risk factors of helicobacter pylori infection in asymptomatic Chinese children: a prospective, cross-sectional, population-based study. Aliment Pharmacol Ther. 2015;42(8):1019-26.

17. Tadesse E, Daka D, Yemane D, Shimelis T. Seroprevalence of helicobacter pylori infection and its related risk factors in symptomatic patients in southern Ethiopia. BMC research notes. 2014;7:834

18. Abebaw W, Kibret M, Abera B. Prevalence and risk factors of H. pylori from dyspeptic patients in Northwest Ethiopia: a hospital based cross-sectional study. Asian Pac J Cancer Prevent. 2014;15(11):4459-63.

19. Taye B, Enquselassie F, Tsegaye A, Amberbir A, Medhin G, Fogarty A, et al. Effect of early and current helicobacter pylori infection on the risk of anaemia in 6.5-year-old Ethiopian children. BMC Infect Dis. 2015;15:270.

20. Miernyk KM, Bulkow LR, Gold BD, Bruce MG, Hurlburt DH, Griffin PM, et al. Prevalence of helicobacter pylori among Alaskans: factors associated with infection and comparison of urea breath test and anti-helicobacter pylori IgG antibodies. Helicobacter. 2018:23(3):e12482.

21. Lim SH, Kwon JW, Kim N, Kim GH, Kang JM, Park MJ, et al. Prevalence and risk factors of helicobacter pylori infection in Korea: nationwide multicenter study over 13 years. BMC Gastroenterol. 2013;13:104.

22. Veldhuyzen van Zanten SJ, Pollak PT, Best LM, Bezanson GS, Marrie T. Increasing prevalence of helicobacter pylori infection with age: continuous risk of infection in adults rather than cohort effect. J Infect Dis. 1994;169(2):434-7.

23. Graham DY, Malaty HM, Evans DG, Evans DJ Jr, Klein PD, Adam E. Epidemiology of helicobacter pylori in an asymptomatic population in the United States. Effect of age, race, and socioeconomic status. Gastroenterology. 1991;100(6):1495-501.

24. Banatvala N, Mayo K, Megraud F, Jennings R, Deeks JJ, Feldman RA. The cohort effect and helicobacter pylori. J Infect Dis. 1993;168(1):219-21.

25. Grimason AM, Davison K, Tembo KC, Jabu GC, Jackson MH. Problems associated with the use of pit latrines in Blantyre, republic of Malawi. J R Soc Promot Heal. 2000;120(3):175-82.

26. Ogihara A, Kikuchi S, Hasegawa A, Kurosawa M, Miki K, Kaneko E, et al. Relationship between helicobacter pylori infection and smoking and drinking habits. J Gastroenterol Hepatol. 2000;15(3):271-6.

27. Chisha Z, Nwosu CO, Ataguba JE. Decomposition of socioeconomic inequalities in cigarette smoking: the case of Namibia. Int J Equity Health. 2019;18(1):6.

28. Lema G, Mesfun MG, Eshete A, Abdeta G. Assessment of status of solid waste management in Asella town, Ethiopia. BMC Public Health. 2019;19(1):1261.

29. Boadi KO, Kuitunen M. Environmental and health impacts of household solid waste handling and disposal practices in third world cities: the case of the Accra metropolitan area. Ghana J Environ Health. 2005;68(4):32-6.

30. Parente JM, da Silva BB, Palha-Dias MP, Zaterka S, Nishimura NF, Zeitune JM. Helicobacter pylori infection in children of low and high socioeconomic status in northeastern Brazil. Am J Tropic Med Hygiene. 2006;75(3):509-12.

\section{Publisher's Note}

Springer Nature remains neutral with regard to jurisdictional claims in published maps and institutional affiliations.

\section{Ready to submit your research? Choose BMC and benefit from:}

- fast, convenient online submission

- thorough peer review by experienced researchers in your field

- rapid publication on acceptance

- support for research data, including large and complex data types

- gold Open Access which fosters wider collaboration and increased citations

- maximum visibility for your research: over $100 \mathrm{M}$ website views per year

At $\mathrm{BMC}$, research is always in progress.

Learn more biomedcentral.com/submission 